Disclosure of Interests: None declared

DOI: 10.1136/annrheumdis-2020-eular.3743

\section{AB0653 SURVIVAL OF BIOLOGIC THERAPHY AS SECOND LINE IN PATIENTS WITH ANKYLOSING SPONDYLITIS. EXPERIENCE IN A TERTIARY CARE CENTRE}

F. López Gutiérrez ${ }^{1}$, V. García García ${ }^{1}$, Á. Andreu-Suárez ${ }^{1}$, B. A. Blanco Cáceres ${ }^{1}$, J. Bachiller-Corral ${ }^{1}$, M. Vázquez Díaz ${ }^{1}$. ${ }^{1}$ Hospital Universitaria Ramón y Cajal, Madrid, Spain

Background: In ankylosing spondylitis (AS) patients with lack of response to a first line of biologic disease modifying antirheumatic drugs (bDMARD), switching to another bDMARD is recommended, aiming either to the same or different therapeutic target. In several previous studies a decrease in drug survival has been noted when tumor necrosis factor alfa inhibitors (TNFai) are used as second or third treatment line $(1,2)$.

Objectives: Primary endpoint: To evaluate survival of bDMARD as second line treatment in patients with AS non responding to TNFai either because of lack or loss of efficacy. Secondary: To evaluate the impact on drug survival of several variables such as sex, HLA, peripheral arthritis, radiologic sacroiliitis, CRP, BASFI, BASDAI or bDMARD class.

Methods: Observational, longitudinal and retrospective observational study. We included 67 patients diagnosed with AS who received treatment on second line with bDMARD (TNFai or anti IL7) after discontinuation of TNFai as first line of treatment. We analyze patients older than 18 yo, with at least 3 months of continuous treatment before and after switch, seen in our Hospital from 2006 to 2019. Data were collected regarding to demographics, HLA B27 positivity and functionality and activity index, CRP and treatment with cDMARDs.

Results: All 67 patients included were still on follow up after switching to second bDMARD. Median age was 37 yo, $56.7 \%$ were male and $31 \%$, smokers. $35.8 \%$ patients had axial AS; $1.5 \%$ peripheral arthritis; $62.7 \%$, mixed and $9 \%$, dactilitis. $76.1 \%$ had radiographic sacroiliitis and $74.6 \%$, HLA B $27+$. As first bDMARD, the most common was Infliximab (IFX) (47.8\%), followed by Adalimumab (ADA) (19.4\%) and Etanercept (ETN 14.9\%). Mean survival was 32.4 months (IFX, 37 months; ETN, 45; Golimumab, 32.3 and ADA, 24.1). The commonest cause of treatment suspension was loss of efficacy (LoE) $(56.7 \%)$, followed by lack of efficacy (LaE) $(17.6 \%)$ and adverse effects (AE) (16.4\%).

As second bDMARD the most frequent was ADA (35.8\%), followed by ETN (34.3\%), Golimumab (9\%), IFX (7.5\%) and Secukinumab $(6 \%)$ with a mean survival of 45 months (ETN 63.8, ADA 45.7, Golimumab 32). Treatment was discontinued in $47.8 \%$ of patients because of $\operatorname{LoE}(17.9 \%)$, LaE $(17.9 \%)$ and EA (11.9\%). A total of $16 \mathrm{AE}$ were recorded, of which $6 \%$ were infections and $9 \%$, allergic reactions. Regarding the analysis of the impact of other variables on drug survival, there was statistically significant differences on HLA B 27 carrier status $(p=0.012)$, in which we observed an increase on survival when the patient is HLA B27 + and in whom BASDAl is higher before switching $(\mathrm{p}=0.02)$.

Conclusion: In our study, we did not observe differences in survival of second line bDMARD in patients with AS regarding type of TNFai, case of discontinuation or type of radiographic involvement in the first line of treatment. Patients with HLA B27+ and high value of BASDAl at the beginning of second bDMARD showed an increased on drug survival. Contrary to literature, we did not see significant differences regarding CRP.

References:

[1] Glintborg B, Østergaard M, Krogh NS, Tarp U, Manilo N, Loft AGR, et al. Clinical response, drug survival and predictors thereof in 432 ankylosing spondylitis patients after switching tumour necrosis factor a inhibitor therapy: results from the Danish nationwide DANBIO registry. Ann Rheum Dis. 2013 Jul;72(7):1149-55.

[2] Deodhar A, Yu D. Switching tumor necrosis factor inhibitors in the treatment of axial spondyloarthritis. Semin Arthritis Rheum. 2017 Dec;47(3):343-50.

Disclosure of Interests: None declared

DOI: 10.1136/annrheumdis-2020-eular.6581

\begin{tabular}{|l|l}
\hline AB0654 & IMPACT OF GENDER ON PATIENT PROFILE \\
& AND TREATMENT RESPONSE IN ANKYLOSING \\
& SPONDYLITIS PATIENTS TREATED WITH TNF-A \\
INHIBITORS
\end{tabular}

B. Milic ${ }^{1}$, T. Ilic ${ }^{1}$, M. Popovic ${ }^{1}$, B. Erdeljan ${ }^{2}$, T. Jankovic ${ }^{1}{ }^{1}$ University of Novi Sad, Medical faculty, Novi Sad, Serbia; ${ }^{2}$ Special Hospital for Rheumatic Diseases Jodna Banja, Novi Sad, Serbia
Background: Ankylosing spondylitis (AS) was historically seen as a predominantly male disease and although recent data showed a more homogenous sex prevalence there is still a long delay and more often a misdiagnosis in women. Also, studies showed that there might be gender-attributable differences regarding clinical characteristics, radiographic damage and response to treatment.

Objectives: The aim of this study was to assess gender differences in AS patients regarding the clinical presentation, disease activity, functional status and response to tumor necrosis factor-alpha inhibitor (TNF-a inhibitor) therapy.

Methods: This retrospective analysis included 59 AS patients treated with first TNF-a inhibitor for at least 12 weeks. TNF-a inhibitor therapy introduction and response was determined according to ASAS-EULAR management recommendations for AS. Clinical and demographic parameters were compared between the female and male patients.

Results: Twenty-four patients $(40,68 \%)$ were females and $35(59,32 \%)$ were males. Women were older than male at moment of study $(p=0,049)$, at the time of diagnosis $(p=0,05)$ and when starting biologic therapy $(p=0,009)$. Moreover, they had a longer diagnosis delay $(p=0,017)$ compared to men. Prevalence of HLA-B27 status and the rate of peripheral arthritis, dactylitis, enthesitis, uveitis or inflammatory bowel disease (IBD) were not different between two groups Disease activity and functional status were also similar in both groups. Males had a significantly longer drug survival time for first biologic $(p=0,031)$. One female patient $(4.2 \%)$ and 4 male patients $(11,4 \%)$ showed primary or secondary inefficacy to TNF- $a$ inhibitor $(p=0,61)$. All 5 non-responders switched to second TNF-a inhibitor and showed a good clinical response. The comparison of the demographic features, clinical characteristics, disease activity, functiona status and response to TNF-a inhibitor therapy according to the gender are presented in Table 1.

Conclusion: In our cohort, the presence of the female gender was related to longer diagnosis delay compared to males. Non-response rate for the first TNF-a inhibitor was similar between groups, but men had longer drug survival time for the first biologic.

\section{References:}

[1] Rusman T, van Vollenhoven RF, van der Horst-Bruinsma IE. Gender differences in axial spondyloarthritis: women are not so lucky. Curr. Rheumatol. Rep. 20(6), 35 (2018).

[2] Van der Heijde D, Ramiro S, Landewe R, et al. (2017): 2016 update of the ASAS-EULAR management recommendations for axial spondyloarthritis. Ann Rheum Dis.76:978-91.

Table 1. Comparison of the baseline demographic, clinical characteristics and treatment response between female and male patients treated with TNF-a inhibitor

\begin{tabular}{|c|c|c|c|}
\hline & $\begin{array}{l}\text { female } \\
(n=24)\end{array}$ & $\begin{array}{c}\text { male } \\
(n=35)\end{array}$ & $\begin{array}{c}P \\
\text { Value }\end{array}$ \\
\hline Age (years), mean \pm SD & $49,08 \pm 12,94$ & $42,56 \pm 11,96$ & 0,049 \\
\hline Age at onset (years), mean $\pm S D$ & $31,6 \pm 9,5$ & $27,7 \pm 9,18$ & 0,117 \\
\hline Age at diagnosis (years), mean $\pm S D$ & $39,02 \pm 11,22$ & $33,06 \pm 11,36$ & 0,05 \\
\hline Diagnosis delay (years), mean $\pm \mathrm{SD}$ & $7,39 \pm 3,45$ & $5,36 \pm 2,86$ & 0,017 \\
\hline Age at TNF- $a$ inhibitor initiation (years), mean \pm SD & $46,4 \pm 12,25$ & $38,08 \pm 11,14$ & 0,009 \\
\hline HLA-B27 positivity n (\%) & $17(70,8 \%)$ & $32(91,4 \%)$ & 0,086 \\
\hline Family history $\mathrm{n}(\%)$ & $10(41,7 \%)$ & $15(42,9 \%)$ & 1 \\
\hline Peripheral arthritis $\mathrm{n}(\%)$ & $16(66,7 \%)$ & $17(48,6 \%)$ & 0,26 \\
\hline Enthesitis $\mathrm{n}(\%)$ & $3(12,5 \%)$ & $6(17,1 \%)$ & 0,9 \\
\hline Dactylitis n (\%) & $0(0 \%)$ & $3(8,6 \%)$ & 0,385 \\
\hline Uveitis n (\%) & $8(33,3 \%)$ & $9(25,7 \%)$ & 0,732 \\
\hline Inflamatory bowel disease n (\%) & $3(12,5 \%)$ & $5(14,3 \%)$ & 1 \\
\hline BASDAI score at TNF- $a$ inhibitor initiation, mean \pm SD & $6,33 \pm 1,69$ & $6,11 \pm 1,77$ & 0,637 \\
\hline BASFI score at TNF- $\alpha$ inhibitor initiation, mean \pm SD & $5,68 \pm 1,39$ & $6,09 \pm 1,39$ & 0,272 \\
\hline ASDAS-CRP score at TNF-a inhibitor initiation, mean \pm SD & $3,87 \pm 0,93$ & $3,78 \pm 1,02$ & 0,743 \\
\hline Duration of first TNF- $a$ inhibitor use (months), mean $_{ \pm}$SD & $35,33 \pm 26,66$ & $51,54 \pm 28,25$ & 0,031 \\
\hline Non-responders to first TNF- $a$ inhibitor $n(\%)$ & $1(4,2 \%)$ & $4(11,4 \%)$ & 0,611 \\
\hline
\end{tabular}

Disclosure of Interests: None declared

DOI: 10.1136/annrheumdis-2020-eular.2047

\begin{tabular}{l|l}
\hline AB0655 & IMPACT OF BIOLOGIC THERAPY ON WORK \\
IMPAIRMENT IN REAL LIFE IN AXIAL \\
SPONDYLOARTHRITIS PATIENTS: DATA FROM \\
REGISPONSERBIO
\end{tabular}

M. Arévalo ${ }^{1}$, M. Moreno ${ }^{1}$, V. Navarro-Compán ${ }^{2}$, F. U. Pilar ${ }^{3}$, E. De Miguel $^{2}$, T. Clavaguera ${ }^{4}$, L. F. Linares Ferrando ${ }^{5}$, B. Joven-Ibáñez ${ }^{6}$, J. GratacosMasmitja $^{1}$, X. Juanola-Roura ${ }^{7}$ on behalf of REGISPONSERBIO Group. ${ }^{1}$ Hospital Universitari Parc Taulí I3PT, Rheumatology, Sabadell, Spain; ${ }^{2}$ Hospital Universitario La Paz, Rheumatology, Madrid, Spain; ${ }^{3}$ Hospital Universitario Reina Sofía IMIBIC, Rheumatology, Córdoba, Spain; 
${ }^{4}$ Hospital Universitari de Girona Doctor Josep Trueta, Rheumatology, Girona, Spain; ${ }^{5}$ Hospital Virgen De La Arrixaca De Murcia, Rheumatology, Murcia, Spain; ${ }^{6}$ Hospital 12 de Octubre, Rheumatology, Madrid, Spain; ${ }^{7}$ Hospital Universitari de Bellvitge, Rheumatology, Hospitalet de Llobregat, Spain

Background: Biologic therapy (BT) has demonstrated its effect in improving work impairment in axial Spondyloarthritis (axSpA) patients in clinical trials, however there is few data of these effects in clinical practice.

Objectives: -To assess the influence of BT in work status using the WPAI questionnaire in patients with axSpA in real life.

-To compare work status between incident and prevalent cases with BT.

-To evaluate factors related to changes in work status in these patients.

Methods: REGISPONSERBIO is an observational, prospective and multicentric Spanish registry of SpA patients under biologic treatment recruited between September 2013 and December 2014. The study includes demographic, radiologic and disease data from both incident (starting biological therapy at the inclusion) and prevalent (already under biologic therapy at the inclusion) patients. WPAI (Work Productivity and Activity Impairment) questionnaire was used to assess work status (employment, lost hours, absenteeism and presenteeism) in both groups of patients at six months after study inclusion. Patients more than 65 years old who were not working were excluded from the analysis, as no changes in work impairment are expected in these individuals.

A descriptive study of work status and related factors was performed using mean and standard deviation as appropriate. Work status was compared between both time-points in incidents and between incidents and prevalents. Uni and multivariate analysis for factors related to baseline work status were assessed, and correlation for change at six months.

Results: The study included 75 incident and 134 prevalent axSpA patients. After start of $B T$, incident patients presented an increase in the number of patients who affirmed to be actively working and an improvement in absenteeism, lost hours and presenteeism, however statistical significance was only reached in the number of hours lost. Comparing incident and prevalent cases, incident patients showed worse data on work status compared to prevalent ones, but only presenteeism reached statistical significance. Factors related to absenteeism and presenteeism at study inclusion were disease activity variables (PGA, BASDAI, ASDAS-CRP), ASQoL and BASFI. Best correlation with improvement in absenteeism at six months was with change in BASDAI (0.84 p 0.07) and age (-0.56 p 0.11), and with improvement in presenteeism were BASFI (0.59 $p 0.002)$, ASQoL (0.57 p 0.002), BASDAI (0.54 p 0.04), PGA (0.51 p 0.01) and ASDAS-CRP(0.51 p 0.01)

Conclusion: Biologic therapy is associated to an improvement in work status in axSpA patients. The results suggest that the fast and high improvement in disease activity and disability observed after start of BT is not directly translated to an improvement in work status at short time. Disease activity, disability and quality of life were the main factors influencing both, work status at inclusion and improvement in absenteeism and presenteeism after BT was started.

Disclosure of Interests: Marta Arévalo: None declared, Mireia Moreno: None declared, Victoria Navarro-Compán Consultant of: Abbvie, Lilly, Novartis, Pfizer, UCB, Speakers bureau: AbbVie, MSD, Lilly, Novartis, Pfizer, UCB, Font Ugalde Pilar: None declared, Eugenio de Miguel Grant/research support from: Yes (Abbvie, Novartis, Pfizer), Consultant of: Yes (Abbvie, Novartis, Pfizer), Paid instructor for: yes (AbbVie, Novartis, Pfizer, MSD, BMS, UCB, Roche, Grunental, Janssen, Sanofi), Speakers bureau: yes (AbbVie, Novartis, Pfizer, MSD, BMS, UCB, Roche, Grunental, Janssen, Sanofi), Teresa Clavaguera Speakers bureau: novartis, BMS, Faes, Luis F. Linares Ferrando: None declared, Beatriz Joven-lbáñez Speakers bureau: Abbvie, Celgene, Janssen, Merck Sharp \& Dohme, Novartis, Pfizer, Jordi Gratacos-Masmitja Grant/research support from: a grant from Pfizzer to study implementation of multidisciplinary units to manage PSA in SPAIN, Consultant of: Pfizzer, MSD, ABBVIE, Janssen, Amgen, BMS, Novartis, Lilly, Speakers bureau: Pfizzer, MSD, ABBVIE, Janssen, Amgen, BMS, Novartis, Lilly, Xavier Juanola-Roura: None declared

DOI: 10.1136/annrheumdis-2020-eular.3150

\section{AB0656 IMPACT OF A FAMILY HISTORY OF SPONDYLOARTHRITIS ON TNFI DRUG SURVIVAL AND TREATMENT RESPONSE IN PATIENTS WITH ANKYLOSING SPONDYLITIS AND PSORIATIC ARTHRITIS}

M. Morin ${ }^{1}$, K. Hellgren ${ }^{1}$, U. Lindström ${ }^{2}$, T. Frisell ${ }^{1} .{ }^{1}$ Karolinska Institutet, Clinical Epidemiology Division, Department of Medicine Solna, Stockholm, Sweden; ${ }^{2}$ Sahlgrenska Academy, University of Gothenburg, Department of Rheumatology and Inflammation Research, Gothenburg, Sweden
Background: Spondyloarthritis $(\mathrm{SpA})$ is known to have high familial aggregation, with a positive family history of SpA being a strong risk factor for disease development, in particular for ankylosing spondylitis (AS). Despite this well-known characteristic of the disease, whether family history is associated with disease prognosis and treatment outcome has been much less studied. Patient characteristics predicting response to tumour necrosis factor alpha inhibitors (TNFi) in SpA include age, sex and high disease activity, but whether family history is predictive of TNFi treatment outcomes remains unclear.

Objectives: To assess if a family history of psoriatic arthritis (PsA), AS, or SpA in general is associated with a different drug survival and treatment response to TNFi in patients with AS and PsA.

Methods: Patients diagnosed with AS $(\mathrm{N}=1688)$ or $\mathrm{PsA}(\mathrm{N}=3216)$ starting their first TNFi treatment between January 2006 and December 2017 were identified in the Swedish Rheumatology Quality Register (SRQ). Disease activity measures were extracted from SRQ at treatment start and at 3 and 12 months of treatment. Data on demographics and comorbidities were available through linkage to other national registries. Multiple imputation was applied to address missing data. Family history was defined as having at least one first-degree relative diagnosed with AS, PsA or any form of SpA in the National Patient Register at start of first TNFi. Analyses were made for AS and PsA index patients separately. Kaplan-Meier plots were used to compare drug survival, and hazard ratios for drug discontinuation were estimated with Cox regression adjusting for age, sex, disease duration and baseline disease activity. The change in disease activity from baseline to 3 months of treatment, and the proportion of patients remaining on treatment at 12 months and reaching low disease activity (LDA) with BASDAI (for AS) and DAS28-CRP (for PsA), were analysed in linear regression adjusting for age, sex, disease duration and baseline disease activity.

Results: A positive family history of AS was found in $14 \%$ of AS patients, and $12 \%$ of PsA patients had a family history of PsA. Characteristics such as age, sex and baseline disease activity were similar in AS patients with and without a family history of AS. Among PsA patients, those with a family history of PsA were to a larger extent female, with lower CRP but longer disease duration. No significant differences were seen in drug survival among patients with and without a family history of their respective disease (Figure 1), with hazard ratios for drug discontinuation of $1.03(95 \% \mathrm{Cl} 0.84$ to 1.27$)$ in AS patients and $1.08(95 \% \mathrm{Cl} 0.94$ to 1.25$)$ in PsA patients. Using family history of any form of SpA as exposure did not change this conclusion. The changes in disease activity at 3 months of treatment compared to baseline were similar between groups. At 12 months, $55.2 \%$ of AS patients with a family history were still on treatment and had a BASDAI corresponding to LDA, compared to $56.4 \%$ of AS patients without a family history. Among PsA patients, $38.7 \%$ of patients with a family history had reached DAS28-CRP LDA, compared to $42.6 \%$ for those without a family history. For both AS and PsA, these differences were non-significant.

Conclusion: While family history of SpA is a strong predictor of disease development, family history was not found to affect neither TNFi drug survival nor treatment response in patients with AS and PsA in this register-based study.

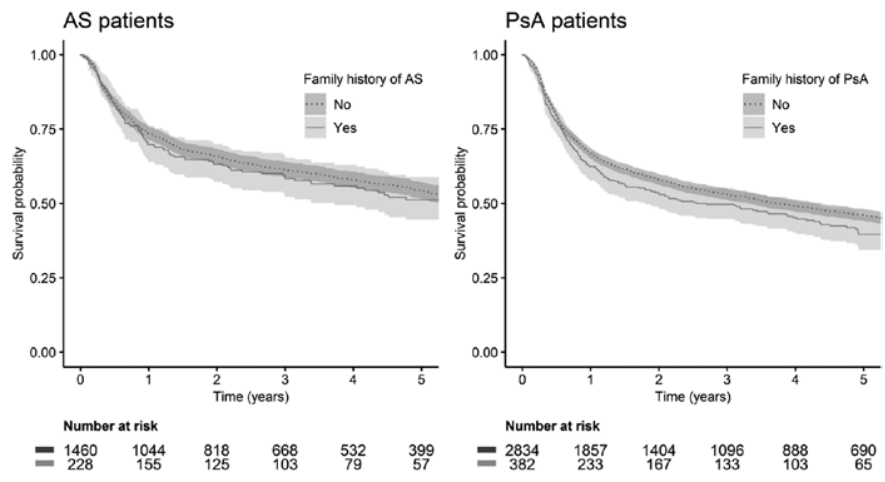

Figure 1. Survival plots for time to TNFi discontinuation in patients diagnosed with AS and PsA respectively, by family history status

Disclosure of Interests: Matilda Morin: None declared, Karin Hellgren Speakers bureau: $\mathrm{KH}$ has received speakers fee from Abbvie and UCB Nordic., Ulf Lindström: None declared, Thomas Frisell: None declared

DOI: 10.1136/annrheumdis-2020-eular.1665 